haemoptysis and a normal chest radiograph. This approach seems clinically reasonable, because chest radiography "misses" small lung cancers and endobronchial lung cancers. However, the combined use of FOB and CT resulted in hundreds of procedures being performed, suggesting that a more efficient process for identifying lung cancers is needed. There are a variety of ways, such as cost-effectiveness analyses, to look at the efficiency of diagnostic strategies. One intriguing approach to compare the efficiency of diagnostic strategies is to calculate the number of tests needed to establish a diagnosis (NTND). This approach appeals to clinicians because it reflects how they solve problems on a daily basis. In a hypothetical analysis of a cohort of patients presenting with haemoptysis and a normal chest radiograph the NTND was calculated for various diagnostic approaches. ${ }^{5}$ Strategies employing either FOB or CT first, followed by the other test if non-diagnostic results were obtained, resulted in a substantial NTND, just as Thirumaran and colleagues reported. ${ }^{1}$ However, a novel approach incorporating the use of sputum cytology as an initial diagnostic test resulted in a substantially lower NTND than either the FOB or CT first approach, while still maintaining a high degree of diagnostic accuracy. Sputum cytology can identify endobronchial lung cancer with a reasonably low false-positive rate. An abnormal sputum cytology would be followed by FOB. An unremarkable sputum cytology could be followed by CT, or by serial chest radiographs.

Haemoptysis with a normal chest radiograph should raise concerns at several levels.
For the individual patient and their doctor, it should raise the suspicion of lung cancer. GPs see many patients with respiratory symptoms, most of which are due to relatively benign causes. Haemoptysis, though, seems to be a more accurate predictor of underlying lung cancer than other respiratory symptoms, such as cough. For the overall healthcare system, a clearer understanding of which patients would benefit from screening for lung cancer is obviously needed. It is curious that the baseline prevalence of lung cancer in LDCT screening trials ranges from $1.3 \%$ to $2.8 \%$, yet the value of lung cancer screening in the asymptomatic patient with a smoking history has not been established. Hopefully, the results of the National Lung Screening Trial, a 50000 patient study evaluating lung cancer mortality in patients undergoing screening with LDCT currently underway in the USA, will clarify this situation. Alternatively, perhaps concentrating on integrating other methods into the screening process, which would identify patients with a higher prevalence of lung cancer, might increase the value of LDCT screening. At present, clinical practice accepts that there are subsets of patients, such as those with haemoptysis and a normal chest radiograph, with an expected higher prevalence of lung cancer who warrant careful evaluation. Clinicians should be aware, though, that there are strategies for searching for lung cancer in these patients which seem to be more efficient than performing $\mathrm{CT}$ and $\mathrm{FOB}$ on every patient.

Competing interests: None.

Provenance and peer review: Commissioned; not externally peer reviewed.

Thorax 2009;64:829-830. doi:10.1136/thx.2009.113191

\section{REFERENCES}

1. Thirumaran $\mathbf{M}$, Sundar R, Sutcliffe $\mathbf{I M}$, et al. Is investigation of patients with haemoptysis and normal chest radiograph justified? Thorax 2009:64:854-6.

2. Quekel LGBA, Kessels AGH, Goei R, et al. Miss rate of lung cancer on the chest radiograph in clinical practice. Chest 1999;115:720-4.

3. Shah PK, Austin JHM, White CS, et al. Missed nonsmall cell lung cancer. Radiology 2003;226:235-41.

4. Hamilton W, Peters TJ, Round A, et al. What are the clinical features of lung cancer before the diagnosis is made? Thorax 2005;60:1059-65.

5. Colice GL. Detecting lung cancer as a cause of hemoptysis in patients with a normal chest radiograph. Chest 1997;111:877-84.

6. Diederich S, Thomas M, Semik M, et al. Screening for early lung cancer with low-dose spiral computed tomography. Eur Radiol 2004;14:691-702.

7. Swensen SJ, Jett JR, Hartman TE, et al. CT screening for lung cancer. Radiology 2005;235:259-65.

8. Gohagan JK, Marcus PM, Fagerstrom RM, et al. Final results of the Lung Screening Study, a randomized feasibility study of spiral CT versus chest $\mathrm{X}$-ray screening for lung cancer. Lung Cancer 2005; 47:9-15

9. Bastarrika G, Garcia-Velloso MJ, Lozano MD, et al. Early lung cancer detection using spiral computed tomography and positron emission tomography. Am J Respir Crit Care Med 2005;171:1378-83.

10. I-ELCAP. Survival of patients with stage I lung cancer detected on CT screening. N Engl J Med 2006;355:1763-71.

11. Blanchon T, Brechot JM, Grenier PA, et al. Baseline results of the Depiscan study. Lung Cancer 2007; 58:50-8

12. Infante $\mathbf{M}$, Lutman FR, Cavuto $\mathrm{S}$, et al. Lung cancer screening with spiral CT. Lung Cancer 2008;59:355-63.

13. Wilson DO, Weissfeld JL, Fuhrman CR, et al. The Pittsburg lung screening study (PluSS). Am J Respir Crit Care Med 2008;178:956-61.

14. Bach PB, Silvestri GA, Hanger M, et al. Screening for lung cancer. Chest 2007;132:S69-77.

15. van lersel CA, de Koning HJ, Draisma G, et al. Riskbased selection from the general population in a screening trial. Int J Cancer 2006;120:868-74.

16. Mazzone P. Progress in the development of a diagnostic test for lung cancer through the analysis of breath volatiles. J Breath Res 2008;2:1-6.

\title{
Blood glucose: of emerging importance in COPD exacerbations
}

\section{Emma H Baker, ${ }^{1}$ Derek Bell ${ }^{2}$}

Elevated blood glucose is a well recognised and common pathophysiological response

\footnotetext{
${ }^{1}$ St George's, University of London, London, UK;

${ }^{2}$ Imperial College, Chelsea and Westminster Hospital, London, UK
}

Correspondence to: Dr Emma Baker, Centre for Clinical Pharmacology, Division of Basic Medical Sciences, St George's, University of London, Cranmer Terrace, London SW17 ORE, UK; ebaker@sgul.ac.uk to acute illness. The underlying mechanisms include acute increases in hepatic glucose production and peripheral insulin resistance, driven by increases in glucocorticoids, catecholamines and proinflammatory cytokines. ${ }^{1}$ Acute hyperglycaemia can occur in any acutely unwell patient, irrespective of baseline glucose tolerance, if the illness is sufficiently severe. Acute hyperglycaemia is associated with poor outcomes from a wide range of acute illnesses including myocardial infarction, ${ }^{2}$ stroke, ${ }^{3}$ trauma ${ }^{4}$ and pneumonia. ${ }^{5}$

The data in relation to hyperglycaemia and acute exacerbations of chronic obstructive pulmonary disease (COPD) are now beginning to emerge. In a previous study, more than $50 \%$ patients with acute exacerbations of COPD had random blood glucose $\geqslant 7 \mathrm{mM}$ during their hospital stay. ${ }^{6}$ This retrospective study could not fully elucidate the relative contributions of acute illness, steroid therapy and underlying diabetes to development of hyperglycaemia. Nevertheless blood glucose $\geqslant 7 \mathrm{mM}$ was significantly associated with increased risk of death or prolonged hospital stay, and the absolute risk of this composite adverse outcome increased by $15 \%$ for each $1 \mathrm{mM}$ increase in blood glucose. 
It is also known that acute hypercapnic respiratory failure is an independent predictor of poor outcome for patients with COPD exacerbations. Non-invasive ventilation (NIV) reduces the likelihood of endotracheal intubation, treatment failure and mortality. ${ }^{7}$ Moretti and colleagues found that "metabolic complications" of COPD exacerbations, including hyperglycaemia defined as blood glucose $>11 \mathrm{mM}$, were independently associated with "late failure" ( $>48 \mathrm{~h})$ of NIV after initial success. ${ }^{8}$ In this study only $\sim 7 \%$ patients had blood glucose $>11 \mathrm{mM}$ and the relationship between more moderate hyperglycaemia $(>6-11 \mathrm{mM})$ and outcomes was not determined. Interestingly all of the patients with late NIV failure who had admission blood glucose $>11 \mathrm{mM}$ subsequently developed pulmonary infection, which may have contributed to NIV failure or death.

The study by Chakrabarti and colleagues in this issue of Thorax (see page 857) investigated the relationship between hyperglycaemia and NIV outcome prospectively in unselected COPD patients with acute hypercapnic respiratory failure. ${ }^{9}$ They found that hyperglycaemia, defined as random blood glucose $\geqslant 7 \mathrm{mM}$ within $24 \mathrm{~h}$ of hospital admission, was present in $50 \%$ patients, consistent with previous findings. ${ }^{6}$ NIV failure was significantly more common in patients with (34\%) than without (2\%) hyperglycaemia, and blood glucose was higher in those in whom NIV failed (mean (SD) 9.0 (3.2) $\mathrm{mM}$ ) than those in whom NIV was successful (7.0 (2.2) mM). This reinforces the concept that even moderate hyperglycaemia may be associated with poorer prognosis in acute illness.

It is not known whether hyperglycaemia is a direct cause of poor outcomes from COPD exacerbations or acts as a marker for other adverse prognostic factors such as treatment variation, comorbidity or severity of acute illness. In their prospective study, Chakrabarti and colleagues provide some new insights into the underlying mechanisms. They found that the association between hyperglycaemia and NIV failure in COPD exacerbations was not explained either by oral corticosteroid use immediately before admission or by underlying diabetes mellitus. Although animal studies have shown that respiratory acidosis causes glucose intolerance by inducing hepatic and peripheral insulin resistance, ${ }^{10}$ in this study hyperglycaemia predicted NIV outcomes independently of $\mathrm{pH}$ and was not merely a marker for low $\mathrm{pH}$. The effect of hyperglycaemia was also independent of
APACHE II (Acute Physiology and Chronic Health Evaluation II) score, a marker of illness severity.

Limitations of the study by Chakrabarti et al include small sample size and lack of information relevant to underlying glucose intolerance such as body mass index and previous episodes of hyperglycaemia during exacerbations. As they point out, glucose was only recorded once on admission and no attempt was made to quantify hyperglycaemia after admission or relate this to outcomes. The authors also do not describe the causes of NIV failure or death in their patients and so have missed an opportunity to explore a causative role for hyperglycaemia in NIV failure. Potential detrimental effects of hyperglycaemia include augmentation of inflammation and infection, and insulin resistance could increase muscle catabolism. Experimental hyperglycaemia induced an acute rise in interleukin-6 (IL-6), tumour necrosis factor $\alpha$ (TNF $\alpha$ ) and IL-18 that was inhibited by glutathione, indicating induction of proinflammatory cytokines via an oxidative mechanism. ${ }^{11}$ C-reactive protein was elevated in people with impaired glucose tolerance compared with those with normal glucose tolerance. ${ }^{12} 13$ In two separate studies of COPD exacerbations, acute hyperglycaemia and underlying diabetes were associated with increased isolation of multiple pathogens and Staphylococcus aureus ${ }^{6}$ and Gram-negative bacteria $^{14}$ from sputum. Hyperglycaemia is associated with elevated glucose concentrations in tissues and bronchial aspirates $^{15}$ where it may stimulate infection by enhancing bacterial growth ${ }^{16}$ and by promoting bacterial interaction with the airway epithelium. ${ }^{17}$ Hyperglycaemia also impairs both innate and adaptive immunity, suppressing the host response to infection. Skeletal muscle abnormalities are common in patients with COPD, and exacerbations requiring hospitalisation are associated with increasing muscle weakness ${ }^{18}$ and reduction in lean body mass. ${ }^{19}$ As insulin is an anabolic hormone, insulin resistance could exacerbate muscle loss during a COPD exacerbation. In support of this, patients with critical illness who did not receive insulin therapy had lower skeletal muscle total protein concentrations than those receiving pharmacological doses of insulin. ${ }^{20}$

The association between hyperglycaemia and poor outcomes raises the important question as to whether correction of hyperglycaemia with insulin could improve outcomes from COPD exacerbations. Initial enthusiasm for tight glycae- mic control in critical illness was generated by a single-centre, randomised controlled trial (RCT) of intensive insulin therapy compared with usual treatment in cardiothoracic patients requiring a stay in an Intensive Care Unit (ICU). ${ }^{21}$ Tight glycaemic control (blood glucose 4.4 $6.1 \mathrm{mM}$ ) reduced mortality by $42 \%$ compared with conventional glycaemic control (blood glucose 10-11.1 mM). In a second RCT by the same investigators in medical ICU patients, tight glycaemic control did not reduce mortality in the whole group but did reduce in-hospital mortality in those requiring a stay in the ICU for $\geqslant 3$ days. ${ }^{22}$ However, patients receiving tight glycaemic control had accelerated weaning from mechanical ventilation and accelerated discharge. Subsequently tight glycaemic control was shown significantly to accelerate resolution of infection ${ }^{21}$ and inflammation, ${ }^{23}$ to prevent nosocomial infection ${ }^{24}$ and to reduce catabolism. ${ }^{2526}$

Benefits of tight glycaemic control for critical illness have become less clear with the recent publication of NICE-SUGAR. ${ }^{27}$ This large RCT, performed in adults expected to require ICU treatment for $\geqslant 3$ days, found that intensive blood glucose control (4.5-6.0 mM) increased mortality (odds ratio 1.14, 95\% CI 1.02 to 1.28) compared with conventional glucose control ( $\leqslant 10 \mathrm{mM}$ ). A meta-analysis of 26 studies including these three large RCTs found no difference in mortality with tight or conventional glycaemic control. ${ }^{28}$ Tight glycaemic control was associated with a sixfold increased risk of hypoglycaemia which may have offset beneficial effects of glycaemic control and insulin therapy. The optimal strategy for management of hyperglycaemia in ICU patients is now unclear, and more moderate glycaemic control (blood glucose 8$10 \mathrm{mM}$ ) is currently recommended. ${ }^{29}$

Despite recent ICU findings, there remains a potential case for testing glycaemic control in patients with COPD with exacerbations requiring hospitalisation. Oral corticosteroids are a key component of exacerbation management in COPD, and subgroup analysis of NICESUGAR suggests heterogeneity of response to glycaemic control in those receiving steroids. ${ }^{29}$ Infection, inflammation and muscle weakness are prominent components of COPD exacerbations and all are improved by glycaemic control with insulin. Most patients with COPD exacerbations, even those requiring NIV, are less critically unwell than those in ICU studies and may be more resistant to the detrimental effects of hypoglycaemia. 
Tight glycaemic control can be implemented in the acute medical unit outside the intensive care setting with similar efficacy and risks of hypoglycaemia as those seen in ICU studies. ${ }^{30}$ However, optimal glycaemic control in COPD remains unclear and ICU studies have shown us that intensive strategies should not be adopted without rigorous testing in multicentre clinical trials.

In their paper, Chakrabarti and colleagues wisely steer clear of discussing the sticky issue of glycaemic control during COPD exacerbations. Rather they concentrate on the interesting finding that blood glucose $<7 \mathrm{mM}$ in combination with respiratory rate $<30 / \mathrm{min}$ predicted a successful outcome from NIV in $97 \%$ of patients with acute hypercapnic respiratory failure. Treatment failure was more likely (but not inevitable) in those with respiratory rate $>30 / \mathrm{min}$ and hyperglycaemia. If their findings are confirmed in other patient cohorts, this simple prognostic index could support discussions with COPD patients and their families prior to initiation of NIV and allow targeting of more intensive monitoring and treatment for those at greater risk of NIV failure. However, measurement of blood glucose is not currently part of NICE/BTS (National Institute for Health and Clinical Excellence/British Thoracic Society) guidelines for the management of COPD exacerbations, ${ }^{31}$ and data about blood glucose were not collected in the 2008 national COPD audit. This paper adds to the growing evidence that hyperglycaemia is important during COPD exacerbations and supports inclusion of blood glucose assessment in future recommendations. However, it does not clarify underlying mechanisms or make the case for tight glycaemic control, both of which require further study.

\section{Competing interests: None.}

Provenance and peer review: Commissioned; not externally peer reviewed.

\section{REFERENCES}

1. Baker EH, Wood DM, Brennan AL, et al. Hyperglycaemia and pulmonary infection. Proc Nutr Soc 2006;65:227-35.

2. Capes SE, Hunt D, Malmberg K, et al. Stress hyperglycaemia and increased risk of death after myocardial infarction in patients with and without diabetes: a systematic overview. Lancet 2000;355:773-8.

3. Capes SE, Hunt D, Malmberg K, et al. Stress hyperglycemia and prognosis of stroke in nondiabetic and diabetic patients: a systematic overview. Stroke 2001;32:2426-32.

4. Yendamuri S, Fulda GJ, Tinkoff GH. Admission hyperglycemia as a prognostic indicator in trauma. J Trauma 2003;55:33-8.

5. McAlister FA, Majumdar SR, Blitz S, et al. The relation between hyperglycemia and outcomes in 2,471 patients admitted to the hospital with community-acquired pneumonia. Diabetes Care 2005:28:810-5.

6. Baker EH, Janaway $\mathrm{CH}$, Philips BJ, et al. Hyperglycaemia is associated with poor outcomes in patients admitted to hospital with acute exacerbations of chronic obstructive pulmonary disease. Thorax 2006:61:284-9.

7. Ram FS, Picot J, Lightowler J, et al. Non-invasive positive pressure ventilation for treatment of respiratory failure due to exacerbations of chronic obstructive pulmonary disease. Cochrane Database Syst Rev 2004;(3):CD004104.

8. Moretti M, Cilione C, Tampieri A, et al. Incidence and causes of non-invasive mechanical ventilation failure after initial success. Thorax 2000;55:819-25.

9. Chakrabarti B, Angus RM, Agarwal S, et al. Hyperglycaemia as a predictor of outcome during non invasive ventilation in decompensated COPD. Thorax 2009;64:857-62

10. Adrogue HJ, Chap Z, Okuda Y, et al. Acidosis-induced glucose intolerance is not prevented by adrenergic blockade. Am J Physiol 1988;255:E812-23.

11. Esposito K, Nappo F, Marfella R, et al. Inflammatory cytokine concentrations are acutely increased by hyperglycemia in humans: role of oxidative stress. Circulation 2002;106:2067-72.

12. Andreozzi F, Succurro E, Mancuso MR, et al. Metabolic and cardiovascular risk factors in subjects with impaired fasting glucose: the 100 versus $110 \mathrm{mg} / \mathrm{dL}$ threshold. Diabetes Metab Res Rev 2007;23:547-50.

13. Choi KM, Lee J, Lee KW, et al. Comparison of serum concentrations of C-reactive protein, TNF-alpha, and interleukin 6 between elderly Korean women with normal and impaired glucose tolerance. Diabetes Res Clin Pract 2004;64:99-106.

14. Loukides S, Polyzogopoulos D. The effect of diabetes mellitus on the outcome of patients with chronic obstructive pulmonary disease exacerbated due to respiratory infections. Respiration 1996;63:170-3.

15. Philips BJ, Redman J, Brennan A, et al. Glucose in bronchial aspirates increases the risk of respiratory MRSA in intubated patients. Thorax 2005;60:761-4.

16. Brennan AL, Gyi KM, Wood DM, et al. Airway glucose concentrations and effect on growth of respiratory pathogens in cystic fibrosis. J Cyst Fibros 2007;6:101-9.

17. Brennan AL, Baines DL, Woollhead A, et al. Development of an in vitro model to investigate the effect of glucose on the interaction between respiratory epithelia and bacterial pathogens. Thorax 2006;61(Suppl II):ii101

18. Spruit MA, Gosselink R, Troosters T, et al. Muscle force during an acute exacerbation in hospitalised patients with COPD and its relationship with CXCL8 and IGF-I. Thorax 2003:58:752-6.

19. Martinez-Llorens JM, Orozco-Levi M, Masdeu MJ et al. [Global muscle dysfunction and exacerbation of COPD: a cohort study]. Med Clin (Barc) 2004;122:521-7.

20. Vanhorebeek I, De VR, Mesotten D, et al. Protection of hepatocyte mitochondrial ultrastructure and function by strict blood glucose control with insulin in critically ill patients. Lancet 2005:365:53-9.

21. Van den Berghe G, Wouters P, Weekers F, et al. Intensive insulin therapy in the critically ill patients. N Engl J Med 2001;345:1359-67.

22. Van den Berghe G, Wilmer A, Hermans G, et al Intensive insulin therapy in the medical ICU. N Engl J Med 2006;354:449-61.

23. Hansen TK, Thiel S, Wouters PJ, et al. Intensive insulin therapy exerts antiinflammatory effects in critically ill patients and counteracts the adverse effect of low mannose-binding lectin levels. J Clin Endocrinol Metab 2003;88:1082-8.

24. Hemmila MR, Taddonio MA, Arbabi S, et al. Intensive insulin therapy is associated with reduced infectious complications in burn patients. Surgery 2008;144:629-37.

25. Ellger B, Richir MC, Van Leeuwen PA, et al. Glycemic control modulates arginine and asymmetricaldimethylarginine levels during critical illness by preserving dimethylarginine-dimethylaminohydrolase activity. Endocrinology 2008:149:3148-57.

26. Biolo G, De CM, Lorenzon S, et al. Treating hyperglycemia improves skeletal muscle protein metabolism in cancer patients after major surgery. Crit Care Med 2008;36:1768-75.

27. Finfer S, Chittock DR, Su SY, et al. Intensive versus conventional glucose control in critically ill patients. $N$ Engl J Med 2009;360:1283-97.

28. Griesdale DE, de Souza RJ, van Dam RM, et al. Intensive insulin therapy and mortality among critically ill patients: a meta-analysis including NICE-SUGAR study data. CMAJ 2009:180:821-7.

29. Bellomo R, Egi M. What is a NICE-SUGAR for patients in the intensive care unit? Mayo Clin Proc 2009;84:400-2.

30. Archer JA, Misra S, Getov S, et al. Feasibility and safety of tight glycaemic control outside the intensive care setting. Br J Clin Pharmacol 2009; in press (abstract).

31. National Collaborating Centre for Chronic Conditions. Chronic obstructive pulmonary disease. National clinical guideline on management of chronic obstructive pulmonary disease in adults in primary and secondary care. Thorax 2004;59(Suppl 1):1-232.

\section{Identification of those at risk after acute pulmonary embolism}

\section{Andrew J Fisher, Paul A Corris}

Northern Pulmonary Vascular Unit, Freeman Hospital and Institute of Cellular Medicine, The Medical School, Newcastle University, Newcastle upon Tyne, UK
Correspondence to: Professor A J Fisher, Institute of Cellular Medicine, The Medical School, Newcastle University, Newcastle upon Tyne NE2 4HH, UK a.j.fisher@newcastle.ac.uk
It is well recognised by hands-on clinicians that patients who present acutely with haemodynamic compromise and hypotension with a systolic pressure of $<90 \mathrm{~mm} \mathrm{Hg}$ due to acute pulmonary embolism (PE) have a poor prognosis. This is reflected in current British Thoracic Society guidelines in the management of acute PE which recommend 